\title{
A Case Report of Conjunctival Squamous Cell Carcinoma in a Patient Wearing an Ocular Prosthesis
}

Randa Falaht, Ana Martinez Palmer, Yasmin Arely Cartagena Guardado, Marta Calsina Prat

Parc De Salut Mar - Hospital De La Esperanza, Barcelona, Spain

\section{Abstract}

A 68-year-old man with chronic use of an ocular prosthesis for phthisis bulbi of his left eye due to

Publication History:

Received: December 24, 2017

ocular trauma 25 years ago was referred to our ophthalmic department with a 6-month history of Published: February 21, 2018 repetitive upper eyelid abscess with poor response to treatment.

Examination revealed upper and lower eyelid edema with erythema, friable tissue of eye socket with tendency to bleed. No areas suspicious for malignancy were noted. Magnetic resonance imaging (MRI) of the orbit revealed an enhancing preseptal orbital mass with signs of focal infiltration into ipsilateral anterior ethmoid cells.

Surgical biopsy was performed, and a segment of the conjunctiva sent for pathology revealed basaloid squamous cell carcinoma. Orbital exenteration was performed followed by various sessions of radiotherapy. This case of a patient who developed squamous cell carcinoma due to long-term placement of an ocular prosthesis confirms the importance of regular inspection of the anophthalmic socket containing prosthesis to rule out conjunctival squamous cell carcinoma is prudent along with a high clinical suspect.

\section{Introduction}

Squamous cell carcinoma (SCCA) of the conjunctiva is an uncommon tumor that arise de novo or from a prior conjunctival or corneal intraepithelial neoplasm [1]. A typical presentation is a slowgrowing mass involving the limbus in the elderly with a complaint of ocular irritation or redness [2].

Various risk factors for conjunctival SCCA have been identified, including excessive exposure to ultraviolet radiation, infection with human papilloma virus (HPV) types 16 and 18 , and human immunodeficiency virus (HIV) [3].

SCCA of the conjunctiva has also been described in association with chronic ocular inflammatory diseases, such as benign mucous membrane pemphigoid, chronic blepharoconjunctivitis, and atopic eczema [3].

Conjunctival SCCA arising in the anophthalmic socket is uncommon; with few reports existing within the literature [3]. The majority of these few cases presented with invasive disease and was treated with orbital exenteration.

We present a case of conjunctival basaloid squamous cell carcinoma, developing in patient with phthisis bulbi and chronic use of an ocular prosthesis, treated with orbital exenteration and radiotherapy.

Consent to use identifiable photographs was signed by the patient and it is filed by authors.

\section{Background}

To describe a case of squamous cell carcinoma of the conjunctiva developed 20 years after ocular trauma that was the cause of phthisis bulbi and chronic use of an ocular prosthesis.

\section{Case Report}

A 68-year-old man, who developed phthisis bulbi of his left eye

\section{Keywords:}

Conjunctival squamous cell carcinoma, Ocular phthisis, Ocular protheses at the age of 42 after ocular trauma, was referred to our ophthalmic department by his general practitioner with a history of repetitive upper eyelid abscess with poor response to various treatments with antibiotics. The patient referred that his symptoms started after having a new prosthesis made 6 months ago.

The patient had worn and renewed his ocular prosthesis regularly during the last 25 years without any significant discomfort.

Aside from the phthisis bulbi, the patient had an unremarkable past medical history. He did not use tobacco and reported that he had no history of chemical or excessive sun exposure.

The ocular examination was significant for upper and lower eyelid edema with erythema, thickening and induration mainly in the medial canthus and friable conjunctival tissue of eye socket with tendency to bleed. No areas suspicious for malignancy were noted.

There was no palpable preauricular or submandibular lymphadenopathy. The initial orbital CT scan showed an inflammatory collection in palpebral and interpalpebral areas with orbit infiltration.

An initial surgical biopsy was taken of the conjunctival tissue. Histopathological examination showed islands of conjunctival basaloid squamous cell carcinoma.

MRI of the orbit with gadolinium revealed an enhancing preseptal orbital mass with dimensions of $3.8 \mathrm{~cm} \mathrm{x} 3.7 \mathrm{~cm} \mathrm{x} 2.6 \mathrm{~cm}$ with involvement of both eyelids and invasion of the retroseptal medial

*Corresponding Author: Dr. Randa Falah, Hospital de la Esperanza, Sant Josep de la Muntanya, 12. Barcelona 08024, Spain, Tel: +34 633144522, Fax: 93 36742 66; Email: randa12hp23@yahoo.com

Citation: Falah R, Palmer AM, Guardado YAC, Prat MC (2018) A Case Report of Conjunctival Squamous Cell Carcinoma in a Patient Wearing an Ocular Prosthesis. Int J Surg Surgical Porced 3: 132. https://doi.org/10.15344/24564443/2018/132

Copyright: (c) 2018 Falah et al. This is an open-access article distributed under the terms of the Creative Commons Attribution License, which permits unrestricted use, distribution, and reproduction in any medium, provided the original author and source are credited. 
Citation: Falah R, Palmer AM, Guardado YAC, Prat MC (2018) A Case Report of Conjunctival Squamous Cell Carcinoma in a Patient Wearing an Ocular Prosthesis. Int J Surg Surgical Porced 3: 132. https://doi.org/10.15344/2456-4443/2018/132

Page 2 of 4

orbit. Signs of focal infiltration into ipsilateral anterior ethmoid cells were reported (Figure 1: Panel A). However, there was no sign of intracranial invasion.
The lesion reached the medial rectus muscle and superior oblique muscle and caused a lateral displacement of the optic nerve. A baseline work-up for systemic disease, including a complete blood cell
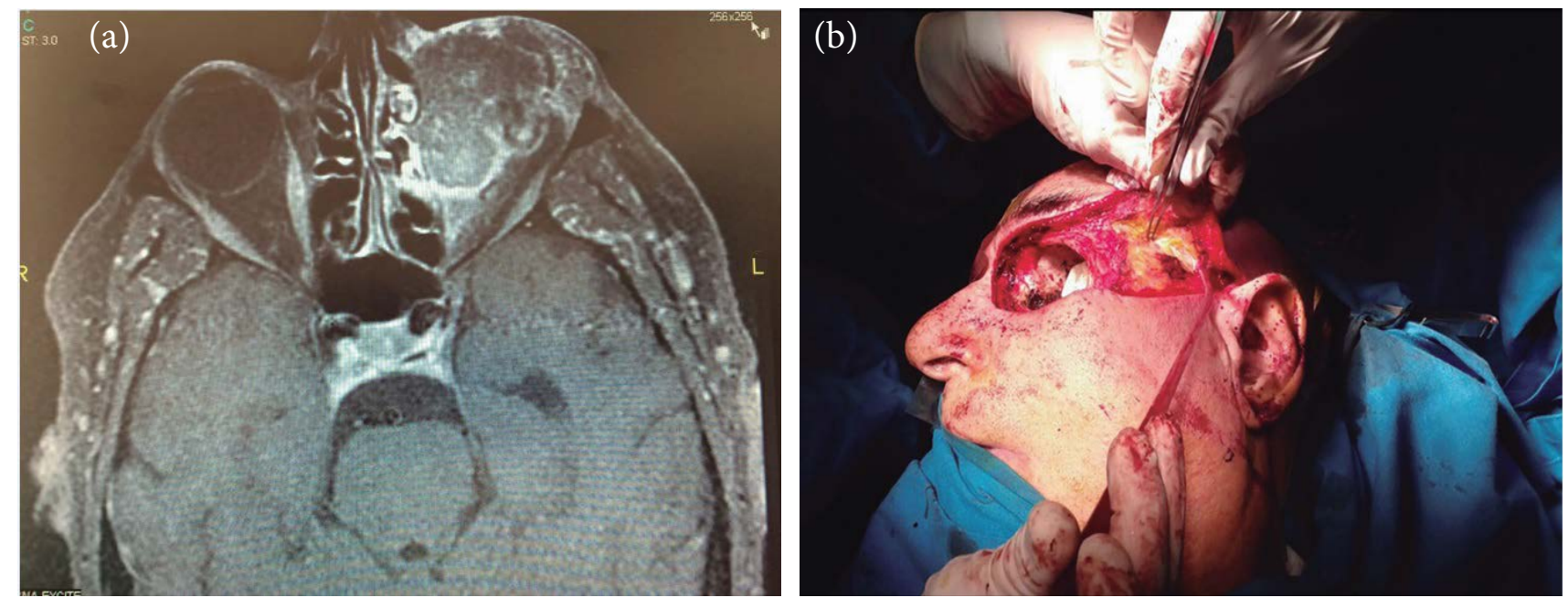

Panel A: Transverse section of MRI of the orbit revealing an preseptal orbital Panel B: Incision and exposure of temporalis fascia and fat pad. mass with invasion of the retroseptal medial orbit.
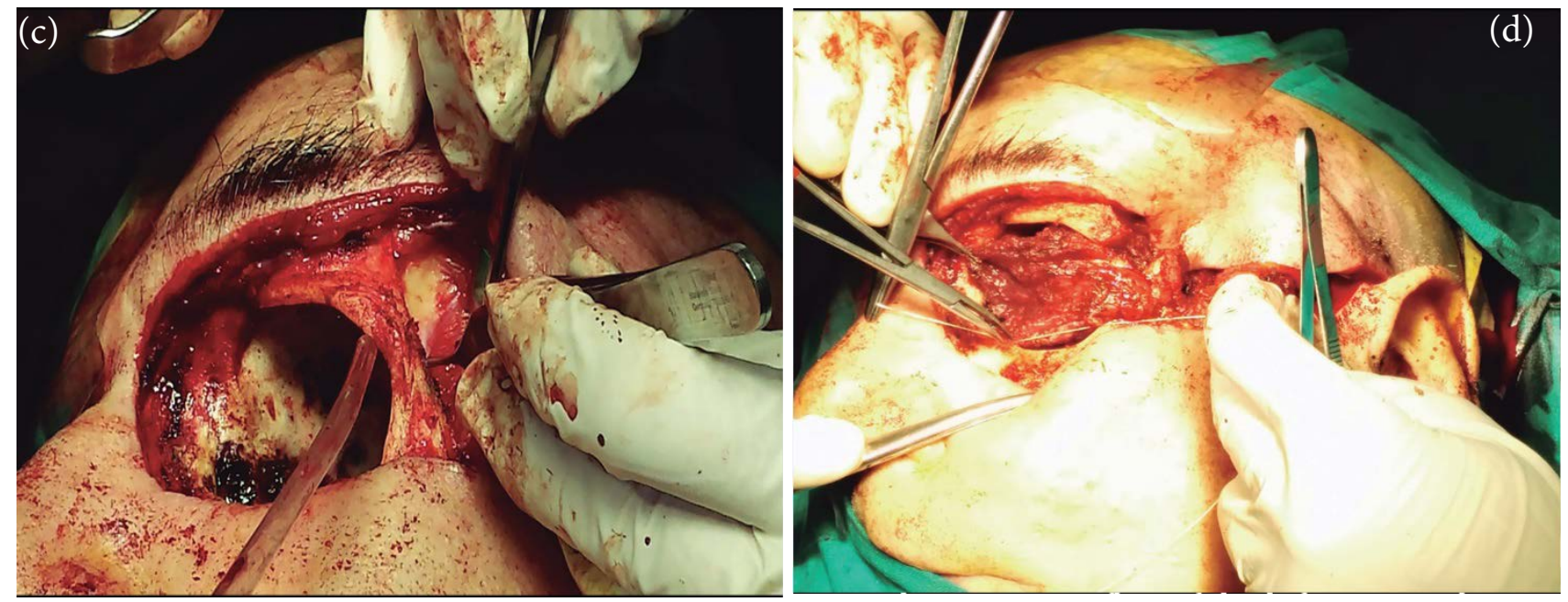

Panel C : Mobilization of left temporal muscle and exposure of zygomatic Panel D: Rotation flap of the left temporal muscle. arch

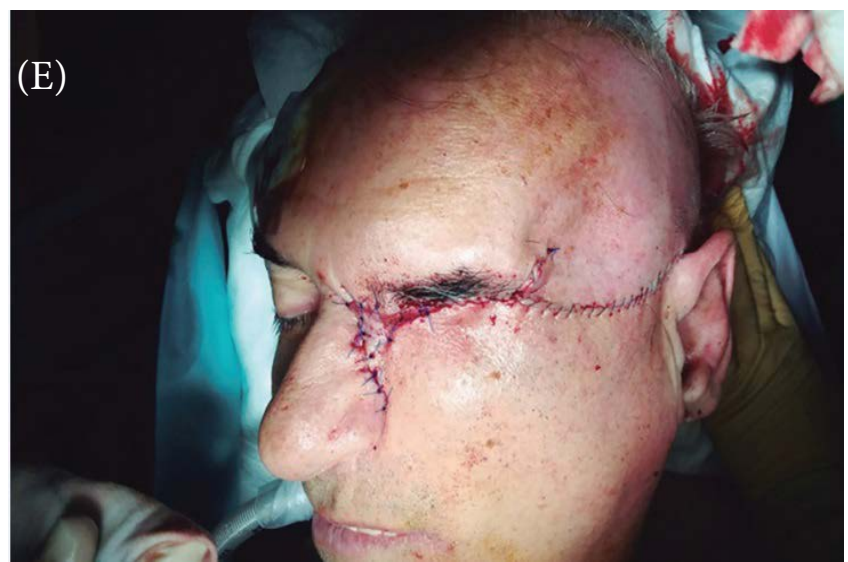

Panel E: Cervicofacialadvancement flap and final suture.

Figure 1: Magnetic resonance imaging (MRI) before surgery with orbital exenteration and reconstruction procedures. 
Citation: Falah R, Palmer AM, Guardado YAC, Prat MC (2018) A Case Report of Conjunctival Squamous Cell Carcinoma in a Patient Wearing an Ocular Prosthesis. Int J Surg Surgical Porced 3: 132. https://doi.org/10.15344/2456-4443/2018/132

Page 3 of 4

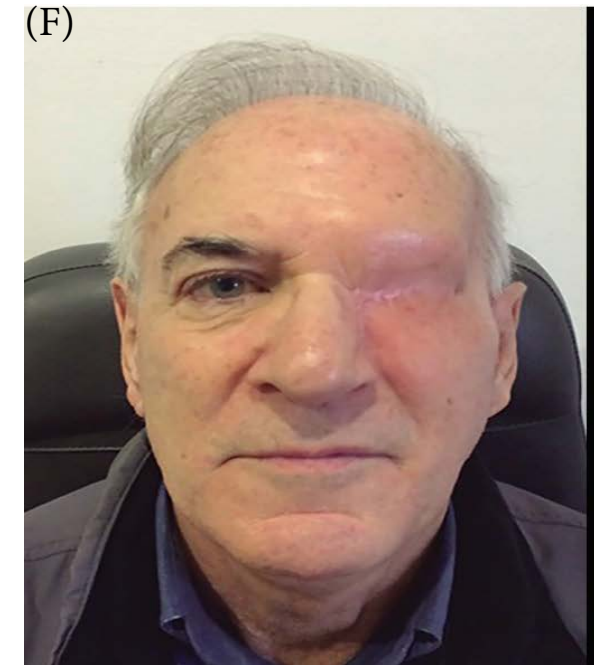

Panel F: Front facial appearance of the patient 1 year after surgery without prosthesis.

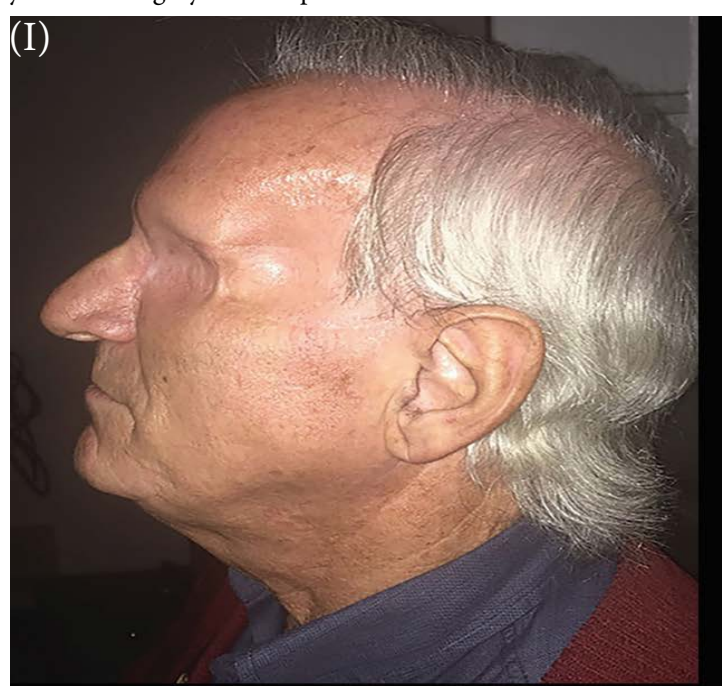

Panel I: Left temporal fossa concavity 2 years after surgery.

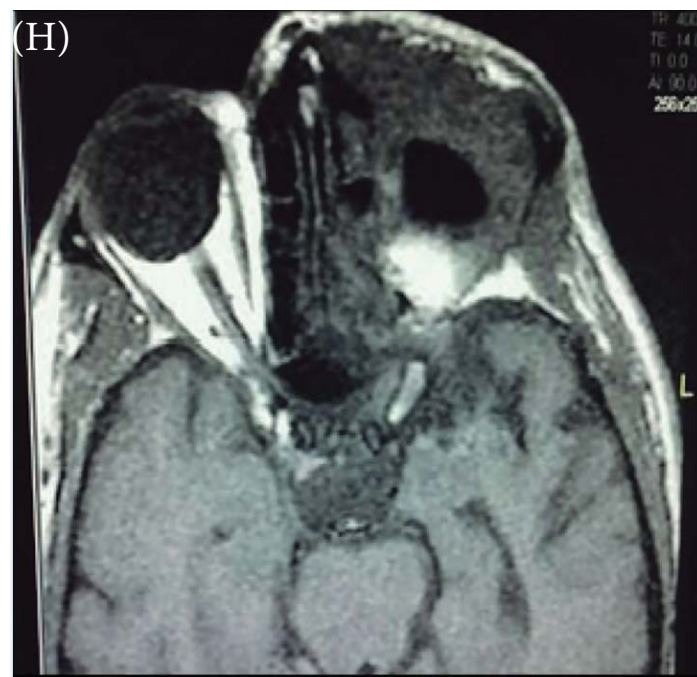

Panel H: Transverse section of MRI of the orbit revealing no sign of tumor.

Figure 2: Magnetic resonance imaging (MRI) and patient's appearance 1 year after surgery (above) and 2 years after surgery (below).

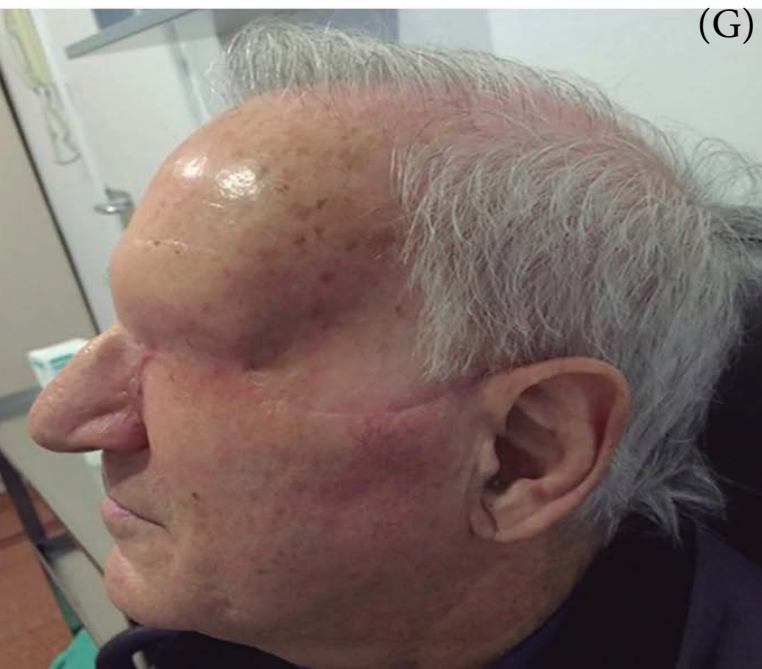

Panel G: Left temporal fossa concavity 1 year after surgery.
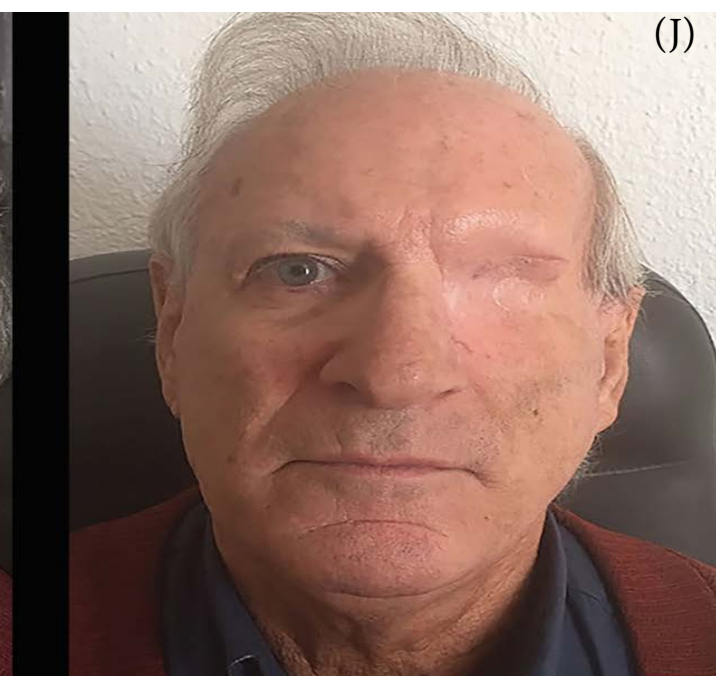

Panel J: Front facial appearance of the patient 2 years after surgery without prosthesis

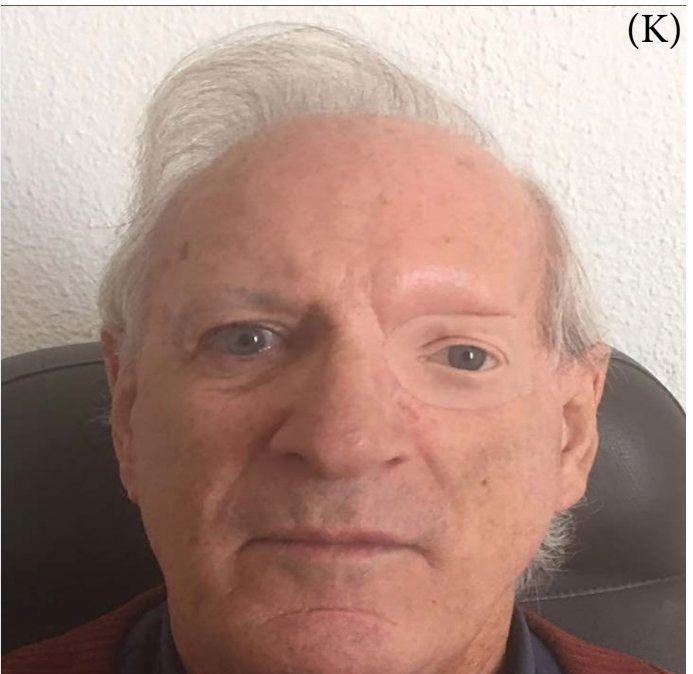

Panel K: Front facial appearance of the patient wearing his prosthesis.

$(\mathrm{K})$ 
count, chemistry panel, liver enzymes panel, and imaging of the chest, abdomen, and pelvis, was negative. Even the otorhinolaryngological exploration was free of lesion macroscopically.

Two weeks later the patient underwent an ocular and orbital exenteration with excision of the skin and conjunctival tumors under frozen section control. Histopathology revealed poorly differentiated conjunctival basaloid squamous cell carcinoma with lesion free margins except for a remaining microscopic contact with the lesion in the medial margin. The remaining eye tissue that was removed and analyzed was free of lesion.

The reconstruction process involved a rotation flap of the left temporal muscle with cervicofacial advancement (Figure 1: Panel $\mathrm{B} \rightarrow \mathrm{E})$.

The reconstruction process involved a rotation flap of the left temporal muscle with cervicofacial advancement (Figure 1: Panel $\mathrm{B} \rightarrow \mathrm{E})$.

\section{Discussion}

Conjunctival SCCA in anophthalmic sockets is quite rare. Few reports of conjunctival SCCA that has developed in an anophthalmic socket exist within the literature [3]. In a recent review on this subject by Vargason et al. a total of ten cases of anophthalmic socket SCC have been summarized, we will mention some of them as examples [4]; Campanella et al. first reported 2 cases of this tumor in 1998 [5]. Chaudhry et al. in 2006 described a growing mass in a patient's left orbit, the eye having been enucleated 50 years ago [6]. In 2011, Espana et al. described a 62 -year-old man presenting 60 years after enucleation with a recurrent lesion after benign papilloma excision 2 years prior [7].

In each of the previously reported cases, prosthesis was worn for at least 40 years [3,6-9], except for 1 case that developed an in-situ SCC after 32 years of wearing the original prosthesis without routine maintenance [4].

In our report, we have described a case of conjunctival SCCA that developedafter 25yearsoflong-termuseofocularprosthesis. Ourpatient had primary involvement of both the bulbar and palpebral conjunctiva with extension in the deep orbital tissues and sparing of the eyelid skin.

Although excessive sun exposure could be a risk factor for developing conjunctival SCCA in general, it was not suspected as one in any of the above-mentioned cases. Other risk factors such as local HPV infection or systemic immunodeficiency disease did not clearly contribute to these cases. Nevertheless, we must mention that in the case described by Gaier et al., the surgically resected SCCA tissue was positive for human papilloma virus serotype [16].

Chronic irritation was speculated as the main contributing factor to the tumor development in these cases. Some of the patients had complained about an ill-fitting prosthesis for a long time [11].

Kim et alreported that although the conjunctiva in the anophthalmic sockets showed squamous metaplasia, there was no correlation between the particular aspects of prosthesis care, including total wearing time and frequency of polishing, and cytologic features of the conjunctival epithelium [12]
In our case, the patient didn't have a poor fitting prosthesis, no ultraviolet exposure of the conjunctival surface, which was covered by the ocular prosthesis, and he did not have any of the other known risk factors for SCCA, such as HIV infection. Therefore, and presuming that prosthesis care has not been related to carcinogenesis, the hypothesis remaining is that chronic irritation or microtrauma between the upper conjunctiva and the prosthesis could be the main trigger for developing SCCA because continuous friction of the prosthesis could easily create these conditions through the daily movement of the upper eyelid.

Others who reported conjunctival SCCA of anophthalmic socket have hypothesized that chronic conjunctival inflammation due to prosthesis use may predispose patients to dysplastic changes, which over time may slowly transform into invasive SCCA $[6,8,9]$.

The relationship between inflammation and cancer is complex. In 1863 Virchow described a lymphoreticular infiltrate within cancer tissue, leading to the hypothesis that cancer arose from sites of chronic inflammation [13].

Once a lesion is detected, several treatment modalities, including surgical excision, cryotherapy, radiation, and a variety of topically applied chemotherapeutic agents exist, including mitomycin C [14].

All the previously reported cases of invasive SCCA in anophthalmic sockets were treated with orbital exenterationwith or without subsequent radiation. The exception was in the in-situ case of Barrett et al. [4] which was treated with excision under frozen section control and reconstruction via a Mustarde flap, hard palategraft, and fornix deepening sutures.

In our case, ocular and orbital exenteration was performed including the upper and lower conjunctiva with total resection of the upper and lower eyelid skin. For the reconstruction of the defect, we chose to use a rotation flap of the left temporal muscle with cervicofacial flap advancement because both the upper and lower eyelid skin were included in the resection. We planned subsequent radiation therapy.

\section{Conclusion}

Conjunctival SCCA that arises from a chronic use of ocular prosthesis is quite rare; however, unlike regular conjunctival SCCA, chronic irritation or microtrauma between upper conjunctiva and prosthesis has been suspected to be the main trigger for the development of this disease.

Our case report adds another example of this rare clinical finding to the literature and adds emphasis that clinicians should be aware of this possible long-term tumor.

\section{Competing Interests}

The authors declare that no competing interests exist.

\section{References}

1. Prado-Serrano A, González-Pérez JV (2009) Carcinoma de células escamosas de conjuntivacon invasión intraocular. Caso clínico. Carcinoma de células escamosas de conjuntiva con invasión. Rev Mex Oftalmol 83 . 245-250. 
Citation: Falah R, Palmer AM, Guardado YAC, Prat MC (2018) A Case Report of Conjunctival Squamous Cell Carcinoma in a Patient Wearing an Ocular Prosthesis. Int J Surg Surgical Porced 3: 132. https://doi.org/10.15344/2456-4443/2018/132

Page 4 of 4

2. McKelvie PA, Daniell M, McNab A, Loughnan M, Santamaria JD, et al (2002) Squamous cell carcinoma of the conjunctiva: a series of 26 cases. $\mathrm{Br} J$ Ophthalmol 86: $168-173$.

3. Nguyen J, Ivan D, Esmaeli B (2008) Conjunctival squamous cell carcinoma in the anophthalmic socket. Ophthalmic Plastic and Reconstructive Surgery 24: $98-101$

4. Barrett RV, Meyer DR, Carlson JA (2010) Conjunctival Squamous CellCarcinoma In Situ in the Anophthalmic Socket. Ophthal Plast Reconstr Surg 26: 52-53

5. Vargason CW, Mawn LA (2017) Management of Inflammation and Periocular Malignancy in the Anophthalmic Socket. Int Ophthalmol Clin 57: 103-116.

6. Campanella PC, Goldberg SH, Erlichman K, Abendroth C (1998) Squamous cell tumors and ocular prostheses. Ophthal Plast Reconstr Surg 14: 45-49

7. Chaudhry TA, Memon M, Ahmad K (2006) Use of artificial eye and conjunctival squamous cell carcinoma. J Postgrad Med 52: 234-235.

8. Espana EM, Levine M, Schoenfield L, Singh AD (2011) Ocular surface squamous neoplasia in an anophthalmic socket 60 years after enucleation. Surv Ophthalmol 56: 539-543.

9. Endo T, Hata J, Togashi S, Yanagibayashi S, Nakayama Y, et al. (2006) Conjunctival squamous cell carcinoma of the orbit 40 years after enucleation. Ophthal Plast Reconstr Surg 22: 299 -301.

10. Whittaker KW, Trivedi D, Bridger J, Sandramouli S (2002) Ocular surface squamous neoplasia: report of an unusual case and review of literature. Orbit 21: 209-215.

11. Gaier ED, Jakobiec FA, Stagner AM, Emerick K, Yoon MK, et al. (2017) HPV16-positive invasive conjunctival squamous cell carcinoma in an anophthalmic socket. Ophthal Plast Reconstr Surg 33: S2-S4

12. Hayashi A, Komoto M, Matsumura T, Horiguchi M, Tanaka R, et al. (2015) Conjunctival Squamous Cell Carcinoma due to Long-term Placement of Ocular Prosthesis. Plast Reconstr Surg Glob Open 3:e325

13. Kim JH, Lee MJ, Choung HK, Kim NJ, Hwang SW, et al. (2008) Conjunctival cytologic features in anophthalmic patients wearing an ocular prosthesis. Ophthal Plast Reconstr Surg 24: 290-295.

14. Balkwill F, Mantovani A (2001) Inflammation and cancer: back to Virchow? Lancet 357: 539-545.

15. Giaconi JA, Karp CL (2003) Current treatment options for conjunctival and corneal intraepithelial neoplasia. Ocular Surface 1: 66-73. 